This article was downloaded by: [134.117.10.200]

On: 19 February 2013, At: 17:24

Publisher: Taylor \& Francis

Informa Ltd Registered in England and Wales Registered Number: 1072954 Registered office: Mortimer House, 37-41 Mortimer Street, London W1T 3J H, UK

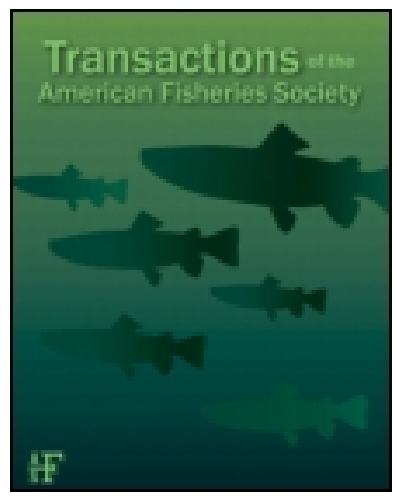

\title{
Transactions of the American Fisheries Society
}

Publication details, including instructions for authors and subscription information:

http:// www. tandfonline.com/loi/ utaf20

\section{Resilience of Pink Salmon and Chum Salmon to Simulated Fisheries Capture Stress Incurred upon Arrival at Spawning Grounds}

Graham D. Raby ${ }^{a}$, Steven J . Cooke ${ }^{a}$, Katrina V. Cook ${ }^{a}$, Sarah H. McConnachie ${ }^{a}$, Michael R. Donaldson ${ }^{b}$, Scott G. Hinch ${ }^{b}$, Charlotte K. Whitney ${ }^{b}$, S. Matthew Drenner ${ }^{b}$, David A. Patterson ${ }^{c}$, Timothy D. Clark ${ }^{d} \&$ Anthony P. Farrell ${ }^{\mathrm{e}}$

${ }^{a}$ Fish Ecology and Conservation Physiology Laboratory, Department of Biology and Institute of Environmental Sciences, Carleton University, 1125 Colonel By Drive, Ottawa, Ontario, K1S 5B6, Canada

${ }^{b}$ Pacific Salmon Ecology and Conservation Laboratory, Department of Forest Sciences and Institute for Resources, Environment and Sustainability, University of British Columbia, 2424 Main Mall, Vancouver, British Columbia, V6T 1Z4, Canada

${ }^{c}$ Fisheries and Oceans Canada, Science Branch, Pacific Region, Cooperative Resource Management Institute, School of Resource and Environmental Management, Simon Fraser University, Burnaby, British Columbia, V5A 1S6, Canada

${ }^{d}$ Australian Institute of Marine Science, Private Mail Box 3, Townsville Mail Centre Q 4810, Townsville, Queensland, Australia

${ }^{\mathrm{e}}$ Department of Zoology and Faculty of Land and Food Systems, University of British Columbia, Vancouver, British Columbia, V6T 1Z4, Canada

Version of record first published: 19 Feb 2013.

To cite this article: Graham D. Raby, Steven J. Cooke, Katrina V. Cook, Sarah H. McConnachie, Michael R. Donaldson , Scott G. Hinch , Charlotte K. Whitney, S. Matthew Drenner, David A. Patterson, Timothy D. Clark \& Anthony P. Farrell (2013): Resilience of Pink Salmon and Chum Salmon to Simulated Fisheries Capture Stress Incurred upon Arrival at Spawning Grounds, Transactions of the American Fisheries Society, 142:2, 524-539

To link to this article: http:// dx.doi.org/ 10.1080/00028487.2012.746241

\section{PLEASE SCROLL DOWN FOR ARTICLE}

Full terms and conditions of use: http://www.tandfonline.com/page/terms-and-conditions

This article may be used for research, teaching, and private study purposes. Any substantial or systematic reproduction, redistribution, reselling, loan, sub-licensing, systematic supply, or distribution in any form to anyone is expressly forbidden.

The publisher does not give any warranty express or implied or make any representation that the contents will be complete or accurate or up to date. The accuracy of any instructions, formulae, and drug doses should be independently verified with primary sources. The publisher shall not be liable for any loss, actions, claims, proceedings, demand, or costs or damages whatsoever or howsoever caused arising directly or indirectly in connection with or arising out of the use of this material. 


\title{
Resilience of Pink Salmon and Chum Salmon to Simulated Fisheries Capture Stress Incurred upon Arrival at Spawning Grounds
}

\author{
Graham D. Raby, * Steven J. Cooke, Katrina V. Cook, and Sarah H. McConnachie \\ Fish Ecology and Conservation Physiology Laboratory, \\ Department of Biology and Institute of Environmental Sciences, Carleton University, \\ 1125 Colonel By Drive, Ottawa, Ontario K1S 5B6, Canada
}

\section{Michael R. Donaldson, Scott G. Hinch, Charlotte K. Whitney, and}

\section{S. Matthew Drenner}

Pacific Salmon Ecology and Conservation Laboratory,

Department of Forest Sciences and Institute for Resources, Environment and Sustainability,

University of British Columbia, 2424 Main Mall, Vancouver, British Columbia V6T 1Z4, Canada

\section{David A. Patterson}

Fisheries and Oceans Canada, Science Branch, Pacific Region, Cooperative Resource Management Institute, School of Resource and Environmental Management, Simon Fraser University, Burnaby, British Columbia V5A 1S6, Canada

\section{Timothy D. Clark}

Australian Institute of Marine Science, Private Mail Box 3, Townsville Mail Centre Q 4810, Townsville, Queensland, Australia

\section{Anthony P. Farrell}

Department of Zoology and Faculty of Land and Food Systems, University of British Columbia, Vancouver, British Columbia V6T 1Z4, Canada

\begin{abstract}
We compared exhaustion-related physiological stress and physical injury as contributors to fish condition, longevity, and egg retention in two Pacific salmon species after their arrival at spawning areas. Adult female Pink Salmon Oncorhynchus gorbuscha and Chum Salmon O. keta were exposed to six experimental capture treatments that represented different levels of exhaustive exercise, air exposure, and injury. After we evaluated its reflex impairment and obtained a blood sample, each fish was released into its natal spawning channel with an external tag and later retrieved postmortem to evaluate spawning success via examining egg retention. Reflex impairment, plasma lactate, chloride, potassium, and osmolality varied among treatments, with differences generally driven by the length of exposure to capture stress, which included exhaustive exercise and air exposure. However, overall prespawn mortality was negligible (about 5\%) and consistent across treatments for both species. We hypothesize that Pink and Chum Salmon are resilient to capture-related exhaustion upon reaching spawning areas because of a combination of low water temperature (about $12^{\circ} \mathrm{C}$ in this study) and a physiological shift towards increased use of anaerobic pathways
\end{abstract}

*Corresponding author: grahamraby@ yahoo.com

Received May 20, 2012; accepted October 25, 2012 


\begin{abstract}
during their final weeks of life. The capture and release of fish arriving at the spawning ground does not appear to influence survival, in contradiction to the results of other studies, which focused on earlier components of Pacific salmon spawning migrations. Fisheries adjacent to spawning sites represent the end of the continuum of salmon fisheries that begin with the high seas fishery and extend through the coastal and riverine environments. The mortality rates in this study should be interpreted cautiously by management until research efforts are broadened to provide a better understanding of how postrelease outcomes at different life stages compare in natural systems and under conditions more representative of real fisheries.
\end{abstract}

There is a growing interest in advancing our understanding of the fate of animals released from fishing gears (Davis 2002; Broadhurst et al. 2006; Donaldson et al. 2008; Davis 2010). By comparing fishing techniques, handling practices, and environmental variables with postrelease outcomes (Davis 2002), research can inform management efforts to reduce or account for postrelease mortality (e.g., Huse and Vold 2010; Gale et al. 2011; Roberts et al. 2011; Baker et al. unpublished data) or improve animal welfare (e.g., Butcher et al. 2011). Fisheries capture involves two general biological effects at the organism level: physiological stress and injury. In the context of fish capture, physiological stress has two parts: (1) a glucocorticoid-based stress response that elicits a cascade of physiological adjustments (Wendelaar Bonga 1997; Barton 2002), and (2) metabolic exhaustion caused by anaerobic exercise and (in many cases) air exposure (Ferguson and Tufts 1992; Kieffer 2000). Physiological stress alone can lead to immediate or delayed mortality (Wood et al. 1983; Ferguson and Tufts 1992; Davis 2007; Gingerich et al. 2007).

Physical injury is the second general organismal effect of fish capture. Injuries could lead to immediate or delayed mortality (Broadhurst et al. 2005), behavioral impairments (Brouwer et al. 2006; Gravel and Cooke 2008), or secondary infections (Baker and Schindler 2009; Butcher et al. 2010). There are also interactions between stress and injury, with injury tending to exacerbate the level of stress. Moreover, the stress response can result in reduced immune function (Barton 2002), which could act in synergy with dermal injuries to produce latent (and potentially fatal) infections. Nevertheless, to our knowledge, no studies have compared the relative effects of (or interactions between) exhaustion-related stress and physical injury on postrelease outcomes. Developing a better understanding of the stress-injury interaction could inform conservation initiatives. For example, if a particular bycatch species proves adept at overcoming fisheries capture stress but suffers high mortality in cases where dermal injuries occur, mortality reduction efforts could focus on reducing injury (e.g., through gear or handling modifications) rather than reducing stress per se (e.g., through reducing net soak times or air exposure).

Physiological measurements have been commonly used to understand the sublethal effects of capture on fishes (Davis et al. 2001; Meka and McCormick 2005; Donaldson et al. 2010), to compare fish welfare outcomes against capture variables (reviewed by Cooke and Sneddon 2007), to develop mortality predictors (Davis et al. 2001; Davis 2007; Campbell et al. 2010), and to evaluate effects on reproductive fitness (Baker et al., in press). Emerging in fisheries research is the use of simple reflex assessments for predicting vitality and delayed mortality (reflex action mortality predictors; Davis and Ottmar 2006; Davis 2007; Humborstad et al. 2009; Davis 2010; Raby et al. 2012) and for evaluating condition of released salmon relative to the use of revival boxes (Farrell et al. 2001; Vander Haegen et al. 2004). Reflex action mortality prediction [RAMP] is a rapid assessment tool that provides an ordinal score that can be used to assess the individual-level effect of capture on fish and predict mortality (Davis 2010). Despite several research papers validating the RAMP approach (Davis and Ottmar 2006; Davis 2007; Humborstad et al. 2009; Campbell et al. 2010; Raby et al. 2012; Donaldson et al. 2012), there has been no demonstration of the processes underlying reflex impairment in fish.

Pacific salmon can be used as a model organism for studying the consequences of capture and release, particularly during the freshwater phase of the spawning migration, where postrelease outcomes can be readily monitored and fitness consequences are clear (Donaldson et al. 2011). Pacific salmon form the basis of one of North America's most lucrative freshwater multisector fisheries. Thousands of metric tons of Fraser River (British Columbia, Canada) Pacific salmon are typically captured and retained annually by recreational, commercial, and aboriginal fisheries (McRae and Pearse 2004; BCMOA 2011). These activities result in capture of nontarget species because of overlap in the migration timing of different species and stocks. Fish are then released back to the river because of regulations or fisher ethic with the hope that they will survive and spawn (Donaldson et al. 2011; Gale et al. 2011; Raby et al. 2012). Yet, there are very few data on the fate of salmon after release from fishing gears in the Fraser River (but see Donaldson et al. 2011; Raby et al. 2012). Also, there is a poor understanding of the factors affecting postrelease mortality. Therefore, studying capture and release in upriver migrating Pacific salmon can both advance our conceptual understanding of bycatch mortality and benefit conservation of an iconic natural resource (Cooke et al. 2012).

Very little data exist on fisheries interactions in river headwaters where salmon are approaching and arriving at terminal spawning areas. Nearly all published studies on salmon capture and release have focused on marine fisheries, and none have investigated postrelease impacts for fish captured upon arrival at spawning areas. Historically, the bulk of harvest fisheries for Pacific salmon did not occur close to spawning areas, with the exception of some small-scale aboriginal fishing. However, in 
some cases there has been an increasing desire for such fisheries that has been motivated by attempts to reduce bycatch and satisfy aboriginal treaty obligations and by an increasing demand for roe. Though the large majority of fishing for Pacific salmon does occur in the marine environment and shortly after river entry, some capture and release occurs close to and within spawning areas. For example, in the Harrison River, one of the largest spawning tributaries of the Fraser River (and the subwatershed where this study took place), there are multiple First Nations fisheries that use gill nets and beach seines: "Economic Opportunity" fisheries (targeting all species), "Food, Social, and Ceremonial" fisheries (all species), and "ESSR" (Excess Salmon for Spawning Requirements) fisheries, which target Chum Salmon Oncorhynchus keta, Coho Salmon O. kisutch, and Pink Salmon O. gorbuscha. Recreational fisheries in the Harrison River targeting mainly Coho Salmon, Chinook Salmon O. tshawytscha, and Sockeye Salmon O. nerka also capture and release thousands of Pink and Chum Salmon. In fact, during 2001 more 45,000 Pink Salmon and 5,000 Chum Salmon were released by anglers on or near spawning areas of the Harrison system. Catchand-release angling also occurs throughout the upper watershed in a similar manner to that in the Harrison River (for data, see http://www.pac.dfo-mpo.gc.ca/fm-gp/fraser/index-eng.htm). In addition, stock assessment managers rely on capture-markrecapture programs that operate in the Harrison system during spawning times to estimate escapement (Chum, Chinook, Sockeye Salmon). More broadly, capture-mark-recapture is one of the most commonly used methods for stock assessment and research in spawning areas, especially in British Columbia (Schwarz et al. 1993; Rajwani and Schwarz 1997; Schubert 2000), but also in the USA and Japan (Miyakoshi and Kudo 1999; Naughton et al. 2009; Parsons and Skalski 2010). Those tagging programs rely on an assumption that the capture and tagging process itself does not affect spawning success.

The primary objective of this study was to elucidate the relative importance of physiological exhaustion and dermal injury as contributors to survival and spawning success in Pink Salmon and Chum Salmon released from fishing gears upon arrival at spawning grounds. A further objective was to evaluate RAMP for the first time in these species while comparing RAMP scores to plasma variables. We sought to apply a range of experimental levels of stress and injury on Pink Salmon and Chum Salmon arriving at spawning grounds, quantify RAMP for each individual, and subsequently monitor their fate after release into a large artificial spawning channel. To our knowledge, this represents the first work on capture-release of either species in any context, two species commonly released by multisector fisheries that harvest Sockeye, Coho, and Chinook Salmon.

\section{METHODS}

All protocols in this study were conducted in accordance with CCAC guidelines and animal care permits obtained from

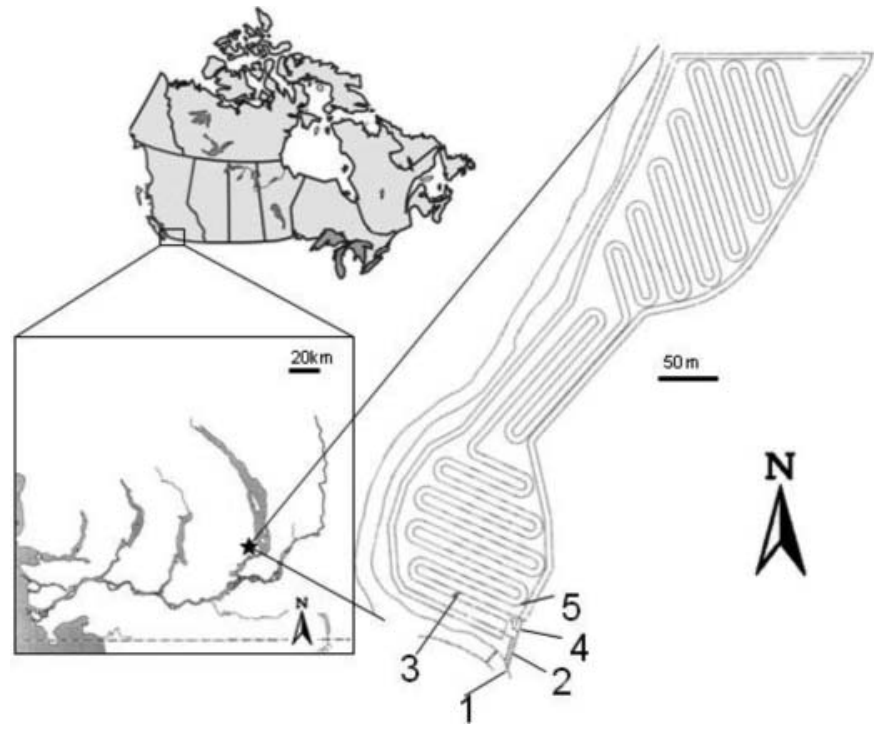

FIGURE 1. Schematic of the Weaver Creek Spawning Channel in the lower Fraser River watershed. The channel segments are as follows: $1=$ the natural Weaver Creek from which fish enter the spawning channel, $2=$ fish ladder entrance to the raceway, $3=$ the sorting shed through which fish are normally allowed to enter the channel or be diverted as surplus, $4=$ the holding area of the raceway from which fish were dipnetted, and $5=$ the location in the downstream-most stretch of the spawning channel into which tagged fish were released following processing. (Source: Hruska et al. 2011 and Cook et al. 2011; used with permission.)

Carleton University and Fisheries and Oceans Canada. The study was conducted at Weaver Creek Spawning Channel, a 2,930-m long, 6.1-m wide, and 0.25-m deep artificial spawning channel built in 1965 as part of British Columbia's Salmonid Enhancement Program (Quinn 1999). The spawning channel is part of the Fraser River watershed and is approximately 117 river kilometers upstream of river entry (Figure 1). Each year in October, Sockeye Salmon O. nerka, Chum Salmon, and Pink Salmon (odd years) enter the spawning channel via a concrete raceway $(2.5 \times 100 \mathrm{~m}, 1.5 \mathrm{~m}$ deep). Individuals are preferentially admitted into the channel through the fence based on preseason spawning targets for each species. Fish not permitted into the spawning channel are either released into the natural creek adjacent the spawning channel or are treated as surplus and harvested by an aboriginal commercial fishery. The channel contains gravel substrate ideal for spawning $(1.2-7.6-\mathrm{cm}$ diameter), has consistent water flow (about $0.4 \mathrm{~m} / \mathrm{s}$ ), and fish densities are controlled. Fish in the raceway are often crowded and have fully developed secondary sexual characteristics, making it easy to dipnet individuals of a particular sex and species. Female salmon were used throughout all experiments to facilitate an accurate assessment of spawning success (see below).

Experimental treatments, biopsy, and tagging.-On October 3-4, 2009, 174 female Pink Salmon (mean water temperature $=13.2^{\circ} \mathrm{C}$ ) and on October 7-12 120 female Chum Salmon $\left(11.8^{\circ} \mathrm{C}\right)$ were dipnetted from the spawning channel raceway and randomly assigned to one of six experimental fishing 
simulation treatment groups: group $1=$ high stress, high injury (i.e., 3 min gill-net entanglement and $1 \mathrm{~min}$ air exposure), $2=$ high stress, minor injury ( 3 min angling with a hook and line, 1 min air exposure), $3=$ high stress, no injury ( 3 min manual chase by hand, $1 \mathrm{~min}$ air exposure), $4=$ low stress, high injury (10 s gill-net entanglement without air exposure), $5=$ low stress minor injury (10 s angling without air exposure), and $6=$ low stress, no injury (control, not subjected to a capture simulation). For all treatments but the control group, fish were immediately transferred from the raceway to a small circular tank ( $2 \mathrm{~m}$ diameter, $0.4 \mathrm{~m}$ deep) continuously supplied with creek water where the capture simulation was undertaken. For the gill-net simulation treatments (groups 1 and 4), fish were placed in the tank and forced to swim into a dip net strung loosely with monofilament gill-net mesh netting (13.3-cm mesh; standard size for targeting Sockeye Salmon in the Fraser River). For the long duration gill-net treatment with air exposure (group 1; hereafter referred to as "high stress"), the fish were disentangled from the net in air and kept in air for a total of 1 min following a 3 min entanglement. For the low stress gill-net treatment (group 4), the fish were kept submerged for disentanglement, which began after only $10 \mathrm{~s}$ in the net. The high stress (group 2) and low stress (group 5) angling treatments mirrored the gill-net treatments, except that in place of a gill-net, a size-1 barbless J-hook attached to a line and rod was inserted through the upper jaw of the fish using pliers and angling was simulated in the circular tank, thus eliciting a hook injury. The chase treatment (group 3) was designed to provide the exhaustive exercise $(3 \mathrm{~min})$ and air exposure ( $1 \mathrm{~min}$ ) of a capture event without any dermal injury; this involved three people leaning over the edge of the tank and stimulating the fish to burst swim by either touching its caudal fin or splashing beside it (Gale et al. 2011). Air exposure involved fish being held in a knotless nylon dip net above ground adjacent to the circular tank for 1 min immediately following cessation of the tank treatment (i.e., 3 min chase, net entanglement, or angling). If gill-net disentanglement for the high stress treatment was not completed within $1 \mathrm{~min}$, disentanglement was completed with the fish submerged in the circular tank. These treatments were intended to be sufficiently varied so that we could make inferences about the relative effects of the injury and exhaustion-related stress components of capture. For example, were higher prespawn mortality to occur in treatments with more severe injuries, irrespective of the level of stress (i.e., exercise and air exposure) imposed, it could be inferred that injury was most influential. Conversely, were the highest mortality to occur in the high stress groups with no differentiation resulting from injuries, one would conclude the exhaustion levels were most influential. Finally, were mortality rates far higher in group 1 (high stress, high injury) than all others, it could be concluded that the interaction between stress and injury is most important.

Upon completion of the capture simulation, each individual was brought to a padded V-shaped sampling trough (described by Cooke et al. 2005), continuously supplied with flowing freshwater directed over the gills, where it was restrained by hand for biopsy and tagging. The control group (group 6) was dipnetted from the raceway and brought directly to the sampling trough for processing (within $10 \mathrm{~s}$ of capture). Each fish was held supine for withdrawal of about $2 \mathrm{~mL}$ of blood using caudal puncture with a 21-gauge needle and a $3-\mathrm{mL}$ heparinized Vacutainer (lithium heparin; BD, Franklin Lakes, New Jersey). Following phlebotomy, an individually numbered cinch tag was inserted through the dorsal musculature anterior to the dorsal fin. Each fish was measured (fork length; $\mathrm{cm}$ ) and any apparent injuries were described. Fish were finally tested with a rapid reflex assessment (see below) and released into the spawning channel (Figure 1). Blood samples were placed in an ice slurry and within 20 min were centrifuged at $10,000 \times$ gravity for 5 min. Plasma samples were flash frozen and stored in liquid nitrogen until later transfer to a $-80^{\circ} \mathrm{C}$ freezer. In the laboratory, we quantified plasma glucose, lactate, osmolality and ions $\left(\mathrm{Cl}^{-}\right.$, $\mathrm{K}^{+}$, and $\mathrm{Na}^{+}$) following the methods described by Farrell et al. (2001). Interassay variation was $<10 \%$ for all assays.

Reflex assessment. - We used reflex action mortality predictors (RAMP; Davis 2010) to assess fish condition and evaluate whether it could predict mortality patterns in Pink and Chum Salmon. The method involves cumulating the presence or absence of five individually-assessed reflexes into an index value (RAMP score); a suite of reflexes previously validated using adult migrating Coho Salmon in the Fraser River (Raby et al. 2012). The reflexes used were identified as being consistently present in vigorous Pink and Chum Salmon in good condition, consistent with the results of other studies using Coho Salmon (Raby et al. 2012) and Sockeye Salmon (Donaldson et al. 2012; G. Raby, unpublished data). The five reflexes tested were tail grab, body flex, head complex, vestibular-ocular response (VOR), and orientation. Tail grab was impaired if, while the fish was immersed in water, a handler attempting to grab the fish around the caudal peduncle did not elicit a burst-swim response. Body flex, assessed by holding the fish out of water with two hands wrapped around the middle of the body, was impaired if the fish did not make an attempt to struggle free (characterized by it flexing its body). Head complex was impaired if the fish failed to demonstrate a pattern of regular ventilation when held out of water for about $5 \mathrm{~s}$. Holding the fish out of water and tilting it onto its side slowly, we assessed VOR by noting the counter-rolling of the eye to maintain level pitch and track, representing a positive response. Either upon release or in the circular tank, the final reflex assessment, orientation, was completed by placing the fish upside down in the water to see whether it would regain orientation; if within $3 \mathrm{~s}$, it was characterized as a positive orientation response, or otherwise ( $>3 \mathrm{~s}$ ), it was an impaired or negative response. The first four reflexes were assessed with the fish in and held out of the water-filled sampling trough. All reflexes were assessed conservatively such that if the researcher had any doubt as to the presence of the reflex, it was assigned an impaired status. The entire RAMP assessment required $<20 \mathrm{~s}$ to complete for each animal and yielded a RAMP score, which represented the 
proportion of reflexes impaired (i.e., $1=$ all reflexes impaired, $0=$ no reflexes impaired). If a fish was too vigorous for handling and assessment of individual reflexes, it was assigned a RAMP score of 0 (following Raby et al. 2012).

Postrelease fate.-Subsequent to release of tagged salmon into the spawning channel, the entire length (about $3 \mathrm{~km}$ ) of the channel was searched twice daily for dead tagged fish. Fish were generally recovered underwater, which was away from most gull scavenging. For each recovered individual, we calculated longevity as the number of days from the date of tagging to the date of recapture. As a proxy for reproductive success, we used egg retention (following Quinn et al. 2007; Hruska et al. 2010, 2011; Cook et al. 2011). For egg retention, we calculated the percentage of eggs remaining in the body cavity relative to the length-specific expected number of total eggs, which was based on length-to-egg-mass relationships we constructed for both Pink and Chum Salmon with separately sampled individuals (Cook et al. 2011, McConnachie et al. 2012). Individuals were then categorized as successful spawners if they had released $>90 \%$ of their eggs, while individuals retaining $50 \%$ or more of their eggs were considered unsuccessful spawners (prespawn mortalities). Fish that had released $51-89 \%$ of their eggs (10 Pink Salmon and 7 Chum Salmon) were excluded from the analysis because small numbers of eggs were sometimes lost from carcasses during transport from the channel to the dissection bench (Cook et al. 2011). Carcasses were carefully inspected for any evidence that they had been stripped of their eggs by gulls. Fish that were not successfully recovered (20 Pink Salmon and 38 Chum Salmon) and fish pecked by gulls (14 Pink Salmon and 4 Chum Salmon) were not included in analyses of egg retention. Thus, assessments of egg retention were based on 130 Pink Salmon and 71 Chum Salmon.

Calibration of the RAMP method.-We conducted an a posteriori experiment using female Pink Salmon to determine the limits of resistance to capture stress and to calibrate a RAMP-mortality curve. Our stress treatment involved aerial confinement in a wetted black Hypalon rubber (chlorosulfonated polyethylene synthetic rubber) fish-holding bag. We used air exposure durations in the range of those used by Gingerich et al. (2007) and Thompson et al. (2008): 0, 60, 120, 240, 480, and 960 s. Pink Salmon females were dipnetted from the spawning channel raceway and randomly assigned to one of the six treatment groups (durations; about 20 per group). Following the aerial confinement stressor, each fish was measured, and cinch-tagged in a water-filled sampling trough as detailed above (except blood samples were not taken). The RAMP assessments were conducted as described above, and the fish were released into the spawning channel in the same location as for the earlier experiment (Figure 1). In addition to the six treatment groups, there was a RAMP control group (total $=132$ fish) that was rapidly dipnetted and RAMPassessed, without the air exposure treatment or the handling associated with tagging. Tagging and release occurred October 19-21, 2009, during which time the mean water temper- ature in the channel was $11.9^{\circ} \mathrm{C}$. Following release, carcasses of tagged individuals were recovered and processed as detailed above.

Data analysis and statistics. - To evaluate the status of fish at the time of release, we compared physiological measures from blood plasma and RAMP scores among treatment groups. The plasma variables we analyzed began changing on a predictable trajectory that was initiated when a fish was first contacted. We therefore used analysis of covariance (ANCOVA) with treatment group as the main effect and handling time (from initial capture to release) as the covariate to compare plasma parameters among treatments (Bonferroni-corrected $\alpha=0.007$ ). Similarly, to compare RAMP scores to plasma variables, we used ANCOVA with RAMP score treated as the categorical main effect and handling time as the covariate $(\alpha=0.008)$. When ANCOVAs were significant, post hoc differences were identified using Tukey's honestly significant difference (HSD) test. The RAMP scores themselves were compared among treatments (in both experiments) using Kruskal-Wallis ANOVA $(\alpha=0.025)$, with multiple comparisons of $z$-values as a post hoc test where necessary. We compared longevity among treatment groups using Kruskal-Wallis ANOVA because the data could not be normalized. In order to compare the proportion of fish categorized as successful spawners among treatment groups, we used a Pearson's chi-square test. To evaluate the predictive power of RAMP score on the fate of released fish, mean longevity was compared among RAMP scores using Kruskal-Wallis ANOVA. Finally, fish were grouped as either spawners or nonspawners, and the RAMP scores at release for those groups were compared using a Mann-Whitney $U$-test. All analyses were conducted using Statistica 8.0 (StatSoft, Tulsa, Oklahoma). Data were normalized using $\log _{10}$ transformation for statistical analyses where necessary following assessment with Shapiro-Wilk $W$ test. All values in text are reported as means \pm standard error of the mean.

\section{RESULTS}

\section{Qualitative Observation of Behavior and Injuries}

Gill net.-Both Pink and Chum Salmon struggled vigorously once they were dipnetted from the raceway into the experimental tank and forced to become entangled in gill-net mesh. Fish from the 10-s entanglement treatment (low stress) remained vigorous as they were being disentangled. Fish from the 3-min treatment (high stress) continued to struggle vigorously for about the first $30 \mathrm{~s}$ of entanglement and then attempted to burst free only periodically for the remainder of the 3-min period. A small number of the Pink Salmon were slender enough to struggle through the gill-net mesh sized used, and had to be reentangled multiple times during the 3-min treatment. Chum Salmon were typically too large for the mesh size used, and therefore the netting functioned as a tangle net with most tangling occurring around the head and on the teeth. Both species occasionally exhibited minor bleeding from the gills as a result of abrasion from the netting, which generally ceased after 1-2 min 
in the sampling trough posttreatment. In general, the gill-net entanglement caused few obvious injuries or scale loss, largely because all fish had reached the point in their lifecycle where their scales had fused into their skin in readiness for the spawning period. The most severe injuries consisted of minor bruising lines from net mesh and localized mucus loss, quite modest relative to injury that can happen in gill-net fisheries further downstream (personal observation of the authors). This treatment generally failed to elicit significant injury partly due to a lack of realism. Salmon capture in most fisheries would suffer damage from the loss of highly perfused scales, plus a range of injury severity depending on fish size, duration of entanglement, and how fish are handled if they are pulled from the gill net by hand and released (rather than escape the net before landing; Baker and Schindler 2009). We caution therefore that the postrelease effects of gill-net entanglement in a true fishery operating at spawning areas would likely differ from what we observed following our gill-net simulation. It remains a possibility that the external physical changes in matured Pacific salmon render them more resilient to gill-net injury than fish at earlier stages, though that possibility has not been sufficiently evaluated here.

Angling.-The angling treatment was effective in that hooked fish typically struggled vigorously for $>2 \mathrm{~min}$, similar to what would be observed in a true angling event (Donaldson et al. 2011). During dehooking or disentangling, whether in water (low stress) or in air (high stress), individuals of both species typically struggled and presumably increased their level of exhaustion. Injuries were consistent for the angling treatment because an identical hook was pulled through the same part of the upper jaw for each individual, leaving a small hole through the tissue and usually minor bleeding. Again, the injuries resulting from this treatment were considered to be minor, and comparable with those obtained during an actual river angling event.

Chase.-The extent of the exercise resulting from the manual chase was similar to what was observed in the high stress angling treatment, where fish would burst vigorously for the first 90-120 s of the treatment before visibly beginning to tire and typically not respond to stimuli towards the end of $3 \mathrm{~min}$. However, we did observe that Chum Salmon typically ceased responding to researcher stimuli 30-60 s earlier than Pink Salmon in the manual chase treatment.

\section{Interactive Effects, RAMP, Blood Physiology, and Fate}

Pink and Chum Salmon responded similarly to the treatments, with RAMP scores and plasma lactate providing the clearest evidence of a treatment effect (Figure 2). After controlling for handling time, the three high stress treatments grouped together in that both Pink and Chum Salmon had significantly higher plasma lactate levels upon release relative to the lowstress injury treatments and controls based on ANCOVA with handling time as a covariate (Pink Salmon: $F_{5,163}=8.72$, $P<0.001$; Chum Salmon: $F_{5,110}=6.48, P<0.001$; Figure 2; Table 1). Similarly, the longer capture simulations that included air exposure resulted in significantly more reflex impairment for both species based on Kruskal-Wallis ANOVA (Pink Salmon: $H_{5,173}=95.53, P<0.001$; Chum Salmon: $H_{5,173}=59.45$, $P<0.001$; Figure 2; Table 1). There was a significant difference in plasma potassium in Pink Salmon among groups $\left(F_{5,163}=\right.$ 8.72, $P<0.001)$, but not in Chum Salmon $\left(F_{5,110}=3.10, P=\right.$ 0.012 ; Table 1). Specifically, a post hoc test revealed that Pink Salmon in the control group had significantly lower levels of plasma potassium than all other groups, while the chase and high stress hook treatments resulted in the highest plasma $\mathrm{K}^{+}$ (Figure 2; Table 1). Treatment also significantly affected plasma chloride $\left(F_{5,164}=3.82, P=0.003\right)$ and osmolality $\left(F_{5,164}=\right.$ $3.74, P=0.003)$ in Pink Salmon after controlling for handling time; osmolality was significantly different among groups in Chum Salmon $\left(F_{5,109}=4.67, P<0.001\right)$, whereas chloride was not $\left(F_{5,110}=2.01, P=0.083\right.$; Figure 2; Table 1$)$. There were no significant effects of the main effect (treatment) or the covariate (handling time) on plasma glucose or sodium in either Pink or Chum Salmon (Table 1).

The pattern of impairment of individual reflexes with successively increasing levels of overall reflex impairment (RAMP scores) was largely consistent. Tail grab and body flex were by far the two most easily impaired reflexes (Tables 2,3). However, in Chum Salmon, tail grab impairment predominated body flex impairment at low RAMP scores $(0.2,0.4)$ compared with Pink Salmon. Orientation was typically the third reflex to become impaired for both species when overall RAMP score increased beyond 0.4 (Tables 2,3 ). We did not commonly observe VOR impairment, which was almost always the last reflex impaired.

The RAMP score also demonstrated some concordance with physiological variables in blood. In particular, lactate accumulation in plasma was significantly related to RAMP score for both Pink $\left(F_{5,163}=3.73, P=0.003\right)$ and Chum Salmon $\left(F_{4,111}=\right.$ $4.75, P=0.001)$, with higher lactate values occurring at higher RAMP scores (Figure 3). Other patterns that were apparent between RAMP scores and plasma constituents (Figure 3) were not statistically significant (Table 1).

Though physiological disturbances were significantly varied among the capture simulations, there were no resulting treatment differences in the postrelease outcomes we measured (Figure 4). Mean postrelease longevity on spawning grounds for female Pink Salmon tagged October $3-4$ in this study was $14.42 \mathrm{~d}$ ( $\mathrm{SE}=$ 0.33 , range $=1-23$ ) and did not differ significantly among the six treatment groups (Kruskal-Wallis ANOVA: $H_{5,154}=4.81$, $P=0.44)$. Mean postrelease longevity on spawning grounds for Chum Salmon was $7.54 \mathrm{~d}(\mathrm{SE}=0.19$, range $=3-12)$, and there was no significant effect of treatment $\left(H_{5,71}=2.53, P=\right.$ 0.77). In general, spawning success was high based on egg retention; 92\% of the released Pink Salmon and 96\% Chum Salmon were categorized as successful spawners. The proportion of fish classed as successful spawners was not significantly different among the six treatment groups for either Pink Salmon (Pearson's chi-square: $\left.\chi^{2}=0.24, P=1.00\right)$ or Chum Salmon $\left(\chi^{2}=\right.$ $0.11, P=1.00)$. With negligible variation in postrelease outcomes, it is not surprising that RAMP score was not a significant 

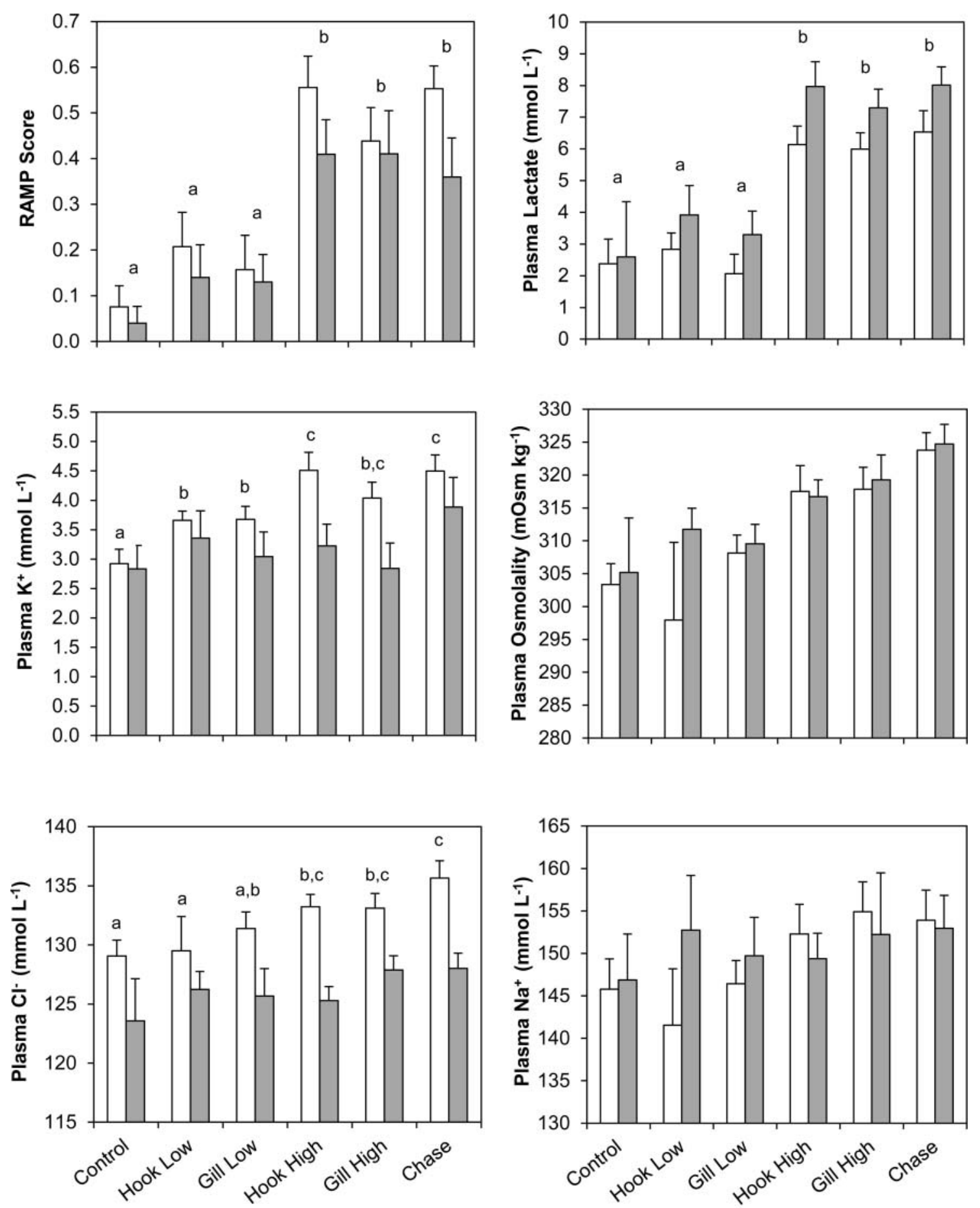

Treatment Group

Treatment Group

FIGURE 2. Mean RAMP scores (see Table 1) as well as plasma lactate, potassium, osmolality, chloride, and sodium values measured in female Pink Salmon (white bars) and Chum Salmon (gray bars) for each of the six capture treatments. The terms "hook low" (treatment 5) and "gill low" (treatment 4) refer to injury treatments with brief exposure to angling and gill netting without air exposure (i.e., low exhaustion stress). The terms "hook high" (treatment 2) and "gill high" (treatment 1) refer to 3-min exposures to the same gears with the addition of 1 min of air exposure. "Chase" (treatment 3) fish were chased in the circular tank for $3 \mathrm{~min}$ followed by $1 \mathrm{~min}$ of air exposure. Control fish (treatment 6) were brought rapidly to the sampling trough for sampling and tagging. Among-group differences were assessed via ANCOVA with researcher handling time as the covariate; post hoc differences among groups are indicated by dissimilar letters. In the first two panels, dissimilar letters denote significant differences among groups for both species; for plasma potassium and chloride, however, there were significant differences only for Pink Salmon. Error bars denote 95\% confidence intervals. 
TABLE 1. Statistical output ( $P$-values) of ANCOVAs comparing physiological differences among experimental capture treatments and levels of reflex impairment (RAMP scores; all treatments pooled), with treatment or RAMP score as the main effect and total researcher handling time as the covariate for both. Differences in RAMP scores (the proportion of reflexes assessed as impaired for an individual among the five reflexes assessed) among capture treatments were assessed with Kruskal-Wallis ANOVA rather than ANCOVA. For treatment effects, $\alpha=0.007$; for RAMP score effects, $\alpha=0.008$. $P$-values in bold italics are significant at Bonferroni-adjusted significance thresholds. Post hoc differences are shown for treatment effects in Figure 2 and for RAMP scores in Figure 3. For Pink Salmon, $n=163$; for Chum Salmon, $n=110$; na $=$ not applicable.

\begin{tabular}{|c|c|c|c|c|}
\hline Variable and species tested & Treatment & Covariate & RAMP score & Covariate \\
\hline \multicolumn{5}{|l|}{ Plasma lactate } \\
\hline Pink Salmon & $<0.001$ & 0.005 & 0.003 & $<0.001$ \\
\hline Chum Salmon & $<0.001$ & 0.232 & 0.001 & $<0.001$ \\
\hline \multicolumn{5}{|l|}{ Plasma glucose } \\
\hline Pink Salmon & 0.796 & 0.363 & 0.913 & 0.573 \\
\hline Chum Salmon & 0.673 & 0.722 & 0.748 & 0.623 \\
\hline \multicolumn{5}{|l|}{ Plasma osmolality } \\
\hline Pink Salmon & 0.003 & 0.053 & 0.492 & $<0.001$ \\
\hline Chum Salmon & $<0.001$ & 0.739 & 0.086 & 0.012 \\
\hline \multicolumn{5}{|l|}{ Plasma $\mathrm{Cl}^{-}$} \\
\hline Pink Salmon & 0.003 & 0.666 & 0.038 & 0.012 \\
\hline Chum Salmon & 0.083 & 0.908 & 0.436 & 0.585 \\
\hline \multicolumn{5}{|l|}{ Plasma $\mathrm{K}^{+}$} \\
\hline Pink Salmon & $<0.001$ & 0.219 & 0.030 & $<0.001$ \\
\hline Chum Salmon & 0.012 & 0.657 & 0.216 & 0.451 \\
\hline \multicolumn{5}{|l|}{ Plasma Na } \\
\hline Pink Salmon & 0.078 & 0.126 & 0.406 & 0.001 \\
\hline Chum Salmon & 0.545 & 0.733 & 0.092 & 0.632 \\
\hline \multicolumn{5}{|l|}{ RAMP score } \\
\hline Pink Salmon & $<0.001$ & na & na & na \\
\hline Chum Salmon & $<0.001$ & na & na & na \\
\hline
\end{tabular}

TABLE 2. Impairment patterns of individual reflexes with increasing overall reflex impairment (RAMP score; see Table 1) in all 305 Pink Salmon exposed to capture simulation treatments. The values are the proportions of individuals with the specified reflex impairments at each level of overall reflex impairment (VOR is vestibular-ocular response).

\begin{tabular}{lccccc}
\hline RAMP score $(n)$ & Tail grab & Body flex & Orientation & Head complex & VOR \\
\hline $0(83)$ & 0 & 0 & 0 & 0 & 0 \\
$0.2(50)$ & 0.60 & 0.36 & 0.02 & 0.02 & 0.02 \\
$0.4(45)$ & 0.84 & 0.71 & 0.42 & 0.12 & 0 \\
$0.6(76)$ & 0.99 & 0.93 & 0.96 & 0.80 & 0 \\
$0.8(30)$ & 1.00 & 0.90 & 1.00 & 1.00 & 0.27 \\
$1.0(21)$ & 1.00 & 1.00 & 1.00 & & 1.00 \\
\hline
\end{tabular}

TABLE 3. Impairment patterns of individual reflexes with increasing overall reflex impairment (RAMP score; see Table 1) in 120 Chum Salmon exposed to capture simulation treatments. The values are the proportions of individuals with the specified reflex impairments at each level of overall reflex impairment.

\begin{tabular}{lccccc}
\hline RAMP score $(n)$ & Tail grab & Body flex & Orientation & Head complex & VOR \\
\hline $0(36)$ & 0 & 0 & 0 & 0 & 0 \\
$0.2(39)$ & 0.87 & 0.08 & 0 & 0.05 & 0 \\
$0.4(26)$ & 1.00 & 0.73 & 0.27 & 0 & 0 \\
$0.6(17)$ & 1.00 & 0.94 & 0.88 & 0.18 & 0 \\
$0.8(2)$ & 1.00 & 1.00 & 1.00 & 1.00 & 0 \\
\hline
\end{tabular}



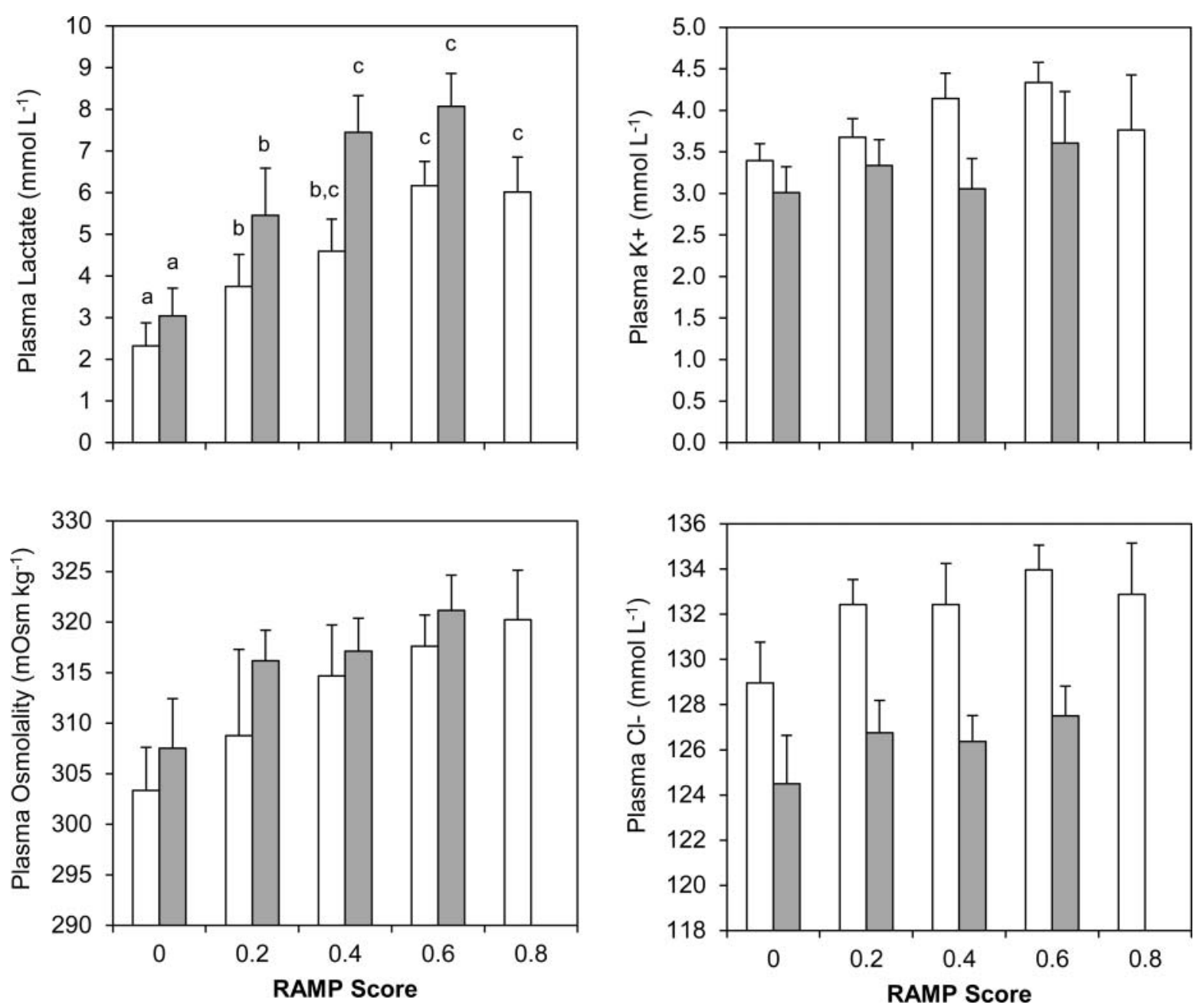

FIGURE 3. Mean plasma lactate, potassium, osmolality, and chloride values for female Pink Salmon (white bars) and Chum Salmon (gray bars) assessed at five different levels (RAMP scores) of overall reflex impairment, higher scores indicating a greater proportion of impaired reflexes. Among-group statistical differences were assessed using ANCOVA with handling time as the covariate and RAMP score as the main effect (categorical) variable. Post hoc among-group differences are denoted by dissimilar letters above bars. Error bars denote $95 \%$ confidence intervals.

predictor of longevity in Pink Salmon (Kruskal-Wallis ANOVA: $\left.H_{5,139}=9.56, P=0.09\right)$ or Chum Salmon $\left(H_{4,78}=5.50\right.$, $P=0.24$ ), nor of spawning success (Mann-Whitney $U$-test, $P$ $=0.87$ for Pink Salmon and $P=0.60$ for Chum Salmon).

An objective of this study was to validate RAMP for these species. However, given that we observed virtually no postrelease (prespawn) mortality to compare with RAMP scores, we conducted an a posteriori experiment using Pink Salmon that involved a range of exhaustion stress beyond that of the main experiment. With each increase in duration of the aerial confinement stressor, we observed an increase in reflex impairment (Figure 5), RAMP scores being significantly different among durations (Kruskal-Wallis ANOVA: $H_{6,132}=108.79, P<0.001$ ). There was an immediate mortality rate (i.e., fish did not leave the release site) of $25 \%$ ( 5 of 20 individuals) for the 960-s (16$\mathrm{min})$ treatment. However, excluding those five individuals, mean overall longevity ( $6.22 \mathrm{~d}, \mathrm{SE}=0.14)$ did not differ significantly among durations $\left(H_{5,75}=7.43, P=0.19\right)$, and every single individual that was recaptured was categorized as a successful spawner, based on low egg retention, including all eight fish recaptured from the 16-min group.

\section{DISCUSSION}

Our study results provide evidence that, after reaching spawning areas, both Pink and Chum Salmon may be resilient to certain forms of capture-related exhaustion stress. Short of producing immediate mortality through extended anoxia, Pink and Chum Salmon are apparently able to recover from substantial physiological disturbance related to capture and ultimately spawn. A primary objective of this study was to tease apart the relative roles of exhaustion-related stress and dermal injury on postrelease outcomes and in particular, prespawn mortality. However, given that we observed little prespawn mortality and 

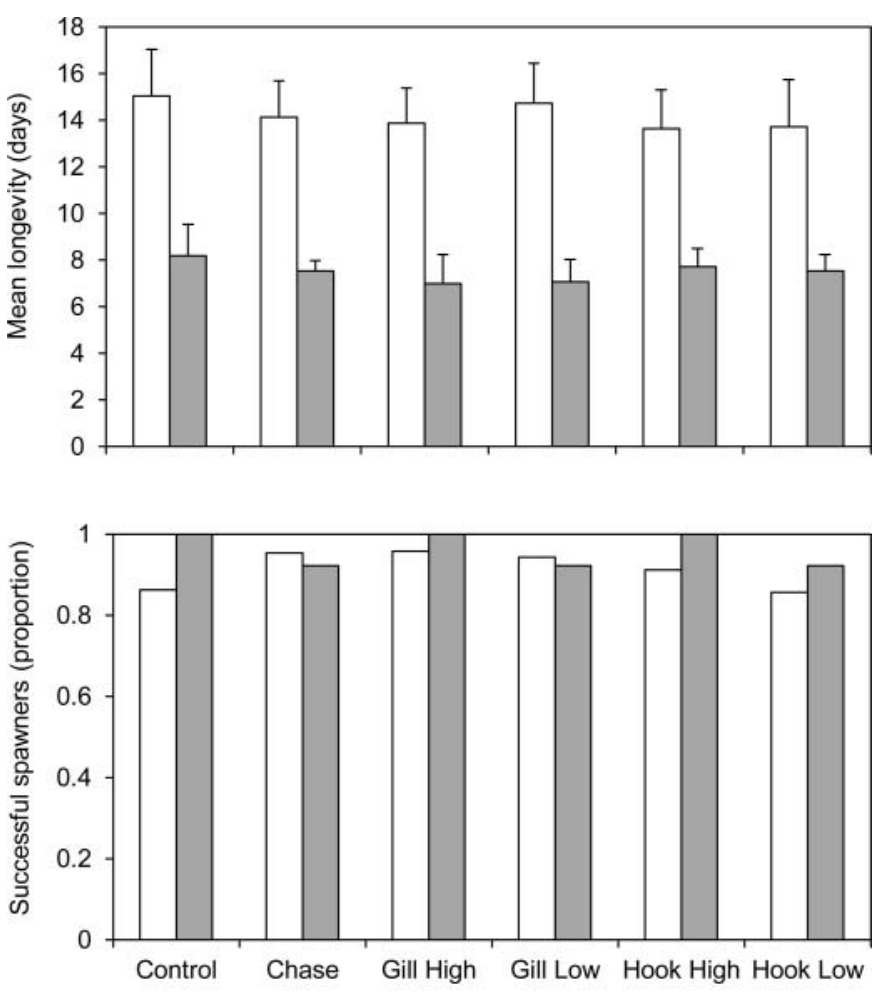

Treatment Group

FIGURE 4. Mean postrelease longevity and the proportion of successful Pink Salmon (white bars) and Chum Salmon (gray bars) spawners for each of the six treatment groups (see Figure 2). Longevity was defined as the number of days from capture and release to postmortem retrieval of the carcass. Individuals were categorized as successful spawners if they retained $\leq 10 \%$ of their eggs following their time on the spawning channel. Error bars denote $95 \%$ confidence intervals.

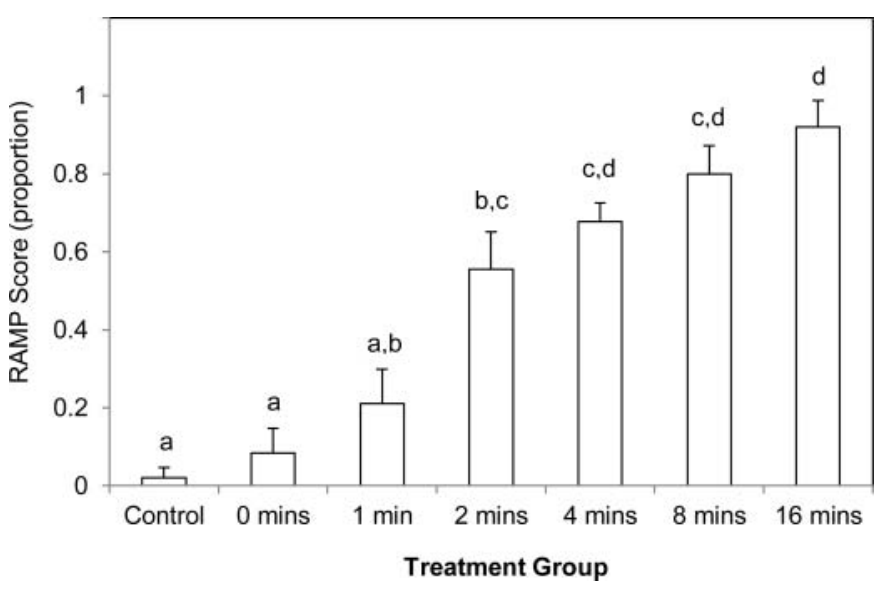

FIGURE 5. Proportion of reflexes assessed as impaired among the five reflexes tested (RAMP scores) in female Pink Salmon following exposure to different durations of an air exposure stressor and cinch-tagging before release into the spawning channel. Control fish were rapidly dipnetted from the channel raceway entrance (see Figure 1) and immediately RAMP-assessed without tagging. Statistical differences among groups were assessed using Kruskal-Wallis ANOVA; post hoc differences are indicated by dissimilar letters. Error bars denote $95 \%$ confidence intervals. no variation in postrelease outcomes among treatments, that objective could not be realized. Natural prespawn mortality rates for Pink Salmon (6.5\%) and Chum Salmon (3.2\%) in the channel during the study year (R. Stitt, Fisheries and Oceans Canada, personal communication) were nearly identical to the prespawn mortality rates for fish subjected to our capture and tagging procedures (Figure 3). It is important to note that our gill-net simulations did not generate severe injuries one would typically observe in a fishery more seaward of the spawning areas (see Baker and Schindler 2009), and thus, we did not adequately evaluate the effects of the injury component of capture. This is partly a shortcoming of the simulation used, but probably also because such injuries may not be possible given the reabsorption of scales and thickened skin in spawning salmon. Future work aimed at disentangling the relative effects of stress and injury should focus on salmon in an earlier state of maturation, before secondary sexual characteristics have been fully developed. Because the injuries generated by our simulations were very minor, the remainder of the paper focuses on discussing apparent resilience to the exhaustion-related stress component of capture rather than injury.

The apparent lack of additive mortality documented here contrasts with previous data on postrelease mortality of Pacific salmon. As noted, some qualifications must be made, including the lack of severe injuries that can occur in real gill-net fisheries. Indeed, analyses of actual exposure to fisheries have often documented extensive delayed mortality for adult Pacific salmon. However, our study is the first to assess mortality following a capture event occurring upon arrival at spawning areas. Pacific salmon captured and released in the ocean have been shown to experience much higher postcapture and release mortality rates: 33-55\% for purse-seine-caught Sockeye Salmon (Cooke et al. 2006), 44\% for troll-caught Coho Salmon (Parker et al. 1959), and up to $75 \%$ for Coho Salmon captured by gill net (Buchanan et al. 2002). During river migration, most studies of capture mortality have focused on recreational angling, with mortality estimates ranging from $1 \%$ to $69 \%$ depending on species, study location, duration of postrelease monitoring, and research techniques (Bendock and Alexandersdottir 1993; Vincent-Lang et al. 1993; Vander Haegen et al. 2004; Nelson et al. 2005; Cowen et al. 2007; Raby et al. 2012). Recent biotelemetry research revealed that angled and released Sockeye Salmon migrating up the lower Fraser River were 20-35\% less likely to reach spawning areas than individuals tagged in the ocean and subsequently tracked in freshwater (Donaldson et al. 2011, in press). Most relevant to our paper was a biotelemetry study conducted at a nearby study site on the Harrison River where Sockeye Salmon (mix of Harrison River and Weaver Creek stocks) were subjected to similar capture simulations approximately 2 weeks earlier in their maturation status (September 10-17, 2009). In that study, Weaver Creek Sockeye Salmon were subjected to the same gill-net treatment as our study (3 min entanglement, $1 \mathrm{~min}$ air exposure), and only $41.7 \%$ successfully reached the spawning channel $(<5 \mathrm{~km}$ away from tagging site; Donaldson et al. 
2012). Among the other three treatment groups (all thought to be less severe than the gill-net treatment), the overall success of fish reaching spawning areas was $32 \%$.

Clearly, survival differences among capture and release studies are wide enough to conclude that mortality rates are highly context-dependent. Nonetheless, we have documented exceptionally low mortality rates for Pink and Chum Salmon and did not observe significant variation in postrelease outcomes, in spite of varied and at times rather severe imposition of physiological stress. Below we propose hypotheses for our unexpected mortality results, discuss our physiological findings, and provide commentary on research and management relevance.

\section{Resilience to Capture Stress}

The moderate water temperature in our study (about $12^{\circ} \mathrm{C}$ ) was probably a contributing factor in the lack of prespawn mortality we observed; a higher mortality would certainly be expected if water was warmer than the optimum temperature of the salmon (Farrell et al. 2008; Gale et al., in press), which was not the case here. Temperature is an important consideration for any study of fisheries-induced mortality. As reviewed by Gale et al. (in press), about $70 \%$ of published capture and release studies with a temperature component have shown a positive relationship between water temperature, indices of stress, and mortality. The bulk of Fraser River fisheries harvest and capture and release occurs in August and September in the lower river, where temperatures typically range from $14^{\circ} \mathrm{C}$ to $18^{\circ} \mathrm{C}$ (Farrell et al. 2008). Indeed, it should be expected that salmon experience cooler temperatures at spawning grounds than during most of upriver migration. Sensitivity to capture is probably not only temperaturedependent, but stock- and species-dependent as well. Recent work has shown that Fraser River salmon stocks vary in their physiological capabilities at higher temperatures (Lee et al. 2003; Clark et al. 2011b; Eliason et al. 2011; Martins et al. 2011) and such interspecific and intraspecific differences can drive differences in mortality rates during upriver migration (Farrell et al. 2008; Tucker et al. 2009; Chittenden et al. 2010; Donaldson et al. 2010; Mathes et al. 2010; Martins et al. 2011). It follows that physiological differences among species and stocks could also translate into differences in resilience to fisheries capture stress.

Disease may be a latent cause of mortality resulting from fisheries capture and release, given the effects that the stress response can have on immune function (Lupes et al. 2006). Chronic exposure to high temperatures during upriver migration can increase the likelihood of natural prespawn mortality by increasing susceptibility to pathogens (Macdonald et al. 2000; Crossin et al. 2008). Had the fish in our study experienced temperature stress during migration, it is possible that the added stress and energetic expenditure associated with capture would have resulted in spawning failure via further acceleration of pathogen development. However, water temperature in the channel itself was moderate, and in many cases there may sim- ply not have been enough time for capture-induced pathogenic prespawn mortality to become manifest, particularly when combined with low temperatures. Irrespective of whether fish in our study were able to spawn before development of captureinduced disease, longevity did not differ among treatments. Given that cortisol is naturally elevated (Hruska et al. 2010) and immune function is already collapsing in spawning salmon (Jeffries et al. 2011), the additive effects of a capture stressor may be relatively insignificant in this respect for spawning salmon. In general, links between fisheries capture and pathogenic mortality remain conceptual and speculative because virtually no published research exists on the topic (see Lupes et al. 2006). Future research could greatly advance the science of delayed fisheries capture mortality by developing an understanding of effects on immune function and pathogen proliferation.

An alternative hypothesis that could explain the lack of observed fitness effects of our capture simulations is the following: as Pacific salmon migrate towards spawning areas they become progressively more resilient to capture as a result of a physiological shift that better equips them to endure challenging environmental conditions, predators, and spawning interactions on spawning grounds. On approach to spawning areas, they undergo a broad-based metabolic shift towards a more frequent use of anaerobic pathways and an increased reliance on protein catabolism (Brett 1995; Miller et al. 2009). Therefore, once salmon have reached spawning grounds they may be particularly adept at enduring and recovering from acute stressors involving heavy use of anaerobic metabolism, and therefore experience no tertiary stress response (i.e., life history consequences) following capture. It is logical that spawning salmon must already be physiologically configured to cope with repeated acute stressors and anaerobic activity associated with general crowding, fighting conspecifics, courtship behaviors, predator evasion, and the air exposure that can occur during migration through shallow streams (Quinn and Buck 2001; Hruska et al. 2010). For example, as part of the maturation process, circulating cortisol can already be at very high levels during spawning activity, particularly for females (Hinch et al. 2006; Hruska et al. 2010). Parallel to our study, Cook et al. (2011) exposed Weaver Creek female Pink Salmon to a rapid blood sample, a 2-min air exposure, and 25-min holding time in fish bags followed by a second blood sampling; they found a spawning failure rate (about 11\%) similar to our study. Individuals with an elevated cortisol response to capture tended to experience spawning failure (Cook et al. 2011), suggesting that intraspecific variation in physiological response to capture could drive postrelease outcomes rather than the intensity of the stressor itself. Indeed, we observed some spawning failure but no significant differences among treatments that differed in stressor intensity.

Finally, some consideration should be given to the potential confounding effects of the artificial nature of the spawning channel used for this study. Weaver Creek Spawning Channel provides uniformly high quality spawning habitat. In addition, fish are let into the channel at rates such that overcrowding (and 
density-dependent mortality) does not occur, theoretically reducing the intensity of competitive interactions relative to that in natural spawning areas. In natural spawning areas, spawning habitat is nonuniform, which creates competition for the areas most suitable for redds. This can result in overcrowding, whereby many fish may not spawn successfully if they are unable to win spawning sites, and others may spawn in lowquality sites producing low embryonic survival. Thus, had the study been replicated using a naturally varied and more crowded spawning area, there may have been differentiation of egg retention among capture treatments. Baker and Schindler (2009) demonstrated that Sockeye Salmon that arrive at spawning areas with gill-net injuries were less likely to enter spawning sites than those without injuries and exhibited reduced longevity. This was partly a result of a retarded maturation process, whereby fish carrying old gill-net wounds did not fully develop secondary sexual characteristics (Baker and Schindler 2009). The injuries in that study were a legacy of gill-net interactions that occurred during the marine approach (i.e., Bristol Bay) areas, where the bulk of Pacific salmon harvest occurs in most systems. For fish with secondary sexual characteristics (including scales being resorbed into skin) captured near spawning grounds, the consequences of injury on maturation, spawning behavior, and egg retention are probably not as pronounced. This may be particularly true if water temperatures are low, slowing the rate of wound infection.

\section{Physiological Findings}

The fishing simulations we used were sufficiently varied in their severity that physiological disturbances differed in extent among treatments. By rapidly dipnetting control fish and sampling blood within 1 min of initial contact, we anticipated that the blood sample would be uninfluenced by the capture event (Clark et al. 2011a). Therefore, control values (Figure 2) were probably representative of the fish's physiological state prior to capture in the channel raceway. Treatments differentiated as we had expected, with the three high-stress simulations being associated with RAMP score and the plasma lactate, osmolality, chloride and potassium values diverging significantly from those of the control fish. Although we did not conduct physiological analyses on white muscle, the increase in both plasma potassium and chloride associated with high stress treatments was probably a result of extracellular water in the plasma shifting to the intracellular compartment, as instigated by muscle acidosis resulting in a higher concentration of ions in plasma (Wood et al. 1983; McDonald and Milligan 1992). Further evidence that these fish were undergoing heavy anaerobic metabolism was provided by an accumulation of plasma lactate in the high stress groups (Figure 2), which was not surprising given that these treatments involved more burst exercise and included $1 \mathrm{~min}$ of air exposure. Collectively, our physiological analyses leave little doubt that the stressors imposed physiological disturbance comparable to what can be expected in some fisheries for Pacific salmon, where postrelease mortality can follow (Farrell et al. 2000; Farrell et al. 2001; Donaldson et al. 2010; Donaldson et al. 2011; Raby et al. 2012; Donaldson et al. 2012).

The potential for RAMP to predict delayed mortality was precluded by the lack of prespawn mortality in this study. Reflex impairment has been previously demonstrated as a predictor of delayed bycatch mortality in migrating Fraser River Coho Salmon (Raby et al. 2012) and in a number of marine species held in captivity (e.g., Davis and Ottmar 2006; Davis 2007; Humborstad et al. 2009). Aside from predicting mortality, RAMP can be used as an integrative whole-body measure of vitality in response to stressors (Davis 2010); indeed, it apparently performed that role in our study, responding to varying degrees of capture stress (Figure 2; Figure 5). The concordance between RAMP scores and plasma constituents (Figure 3) in our study was novel. Although the RAMP score showed general agreement with plasma osmolality, chloride, and potassium (though not significant), it was most strongly and significantly associated with plasma lactate (Figure 3), which is not surprising because plasma lactate is a byproduct of anaerobic exercise (McDonald and Milligan 1992). These are the first data to provide some confirmation that reflex impairment indicates a compromised physiological state. We suggest, however, that plasma lactate is not itself a driver of reflex impairment but rather a byproduct of the physiological processes directly responsible for impairment of at least some of the reflexes we tested. In this and other studies using RAMP with Pacific salmon, we have repeatedly observed that exhausted salmon can recover their reflex actions after a short recovery (15-30 min; G. Raby and M. Donaldson, unpublished data), whereas plasma lactate typically does not peak until 1-2 h after capture and often does not return to baseline levels for 10 h (e.g., Parker et al. 1959; Wood et al. 1983; Ferguson and Tufts 1992; Farrell et al. 2001; Cech et al. 2004; Clark et al. 2012). Moreover, RAMP scores were not associated with plasma lactate in blood sampled and RAMP-assessed Coho Salmon bycatch that had recovered for a range of durations $<30$ min (Raby et al. 2012); presumably because lactate continued to accumulate in plasma, whereas reflex impairment began to decrease during recovery. Other physiological measurements indicative of exhaustion that recover more quickly would therefore probably reveal more about what drives reflex impairment (e.g., lactate, adenosine triphosphate, and phosphocreatine in white muscle; Farrell et al. 2001; Suski et al. 2007; Raby et al. 2012); however, different reflex impairments may be associated with different types of physiological disturbances (e.g., pathway to VOR impairment may differ from that of tail grab). Our study serves as a first proof of concept for RAMP with Pink and Chum Salmon. We expect that further research in a fisheries context, where substantial mortality actually occurs, would probably reveal a mortality correlation with reflex impairment, as has been observed for adult Coho Salmon (Raby et al. 2012) and Sockeye Salmon (Gale et al. 2011; Donaldson et al. 2012). 


\section{Management Implications and Future Research}

Our finding that Pink and Chum Salmon may be resilient to capture stress at the final stage of maturation as they reach spawning areas should be of interest to managers and scientists concerned with Pacific salmon. However, it should be made abundantly clear that the prespawn mortality rate we documented here (near zero) for salmon should not be considered a usable estimate for migrating salmon that experience a comparable capture stressor, nor was it our objective to generate such an estimate. The capture stressors in this study were simulated and, in the case of the gill-net simulation, probably quite mild compared to a real fishery, particularly with respect to the injuries generated. In addition, most capture and release of Pacific salmon occurs much earlier in the migration than upon arrival at spawning areas. Nonetheless, there are fisheries near terminal spawning grounds in the Fraser River basin, largely conducted by recreational anglers and by aboriginal groups using beach seines, dip nets, and gill nets. Our results are relevant to the release of nontarget fish caught by these groups on or adjacent to spawning areas. Such gears enable selective harvest, so release of fish certainly occurs.

As discussed, the fish in our study may have been physiologically equipped to better endure acute stress exposure than they would be earlier in their migration. As far as we are aware, this is the first study on capture and release of Pink or Chum Salmon in any context in the peer-reviewed literature, so it remains possible that these two species are more resilient to capture than Sockeye, Coho, and Chinook Salmon. The capture-mark-recapture programs conducted on spawning grounds for stock assessment purposes for Fraser River salmon assume negligible mortality from seine capture and external tagging with Petersen discs. The data presented here support that assumption. Our findings also bring light to the difficult issue that postrelease mortality is dependent on biological context. For example, a mortality estimate for Coho Salmon released from a gill net shortly after river entry may not be transferrable to the same fishery taking place $120 \mathrm{~km}$ upstream. Temporal sequence could be a factor. In the above-mentioned study by Donaldson et al. (2012), Weaver Creek Sockeye Salmon captured about 2 weeks earlier in their maturation status than our fish and released $5 \mathrm{~km}$ away in the Harrison River experienced mortality nearly 10 times that of our fish. In our study there was evidence for a maturation status effect, whereby later arriving fish that were captured and tagged closer to senescence had higher rates of spawning success. Stock and species differences further complicate management decisions on assigning mortality rates to fisheries bycatch to meet escapement targets (Baker and Schindler 2009).

Evidently, developing a better understanding of how interspecific, intraspecific, and interpopulation differences govern sensitivity to capture could greatly improve the efficacy of Pacific salmon management. Validating rapid and inexpensive mortality predictors like RAMP may be the most efficient avenue for researchers and managers, given that such tools could quickly generate mortality estimates across different contexts
(Raby et al. 2012). Finally, better understanding of the relative importance of and interaction between physiological exhaustion and dermal injury in bycatch releases should remain a research priority. Studies that use an experimental approach and unveil mechanisms can serve as the basis for solutions to unobserved fishing mortality.

\section{ACKNOWLEDGMENTS}

We are grateful to R. Stitt, W. Charlie, and the employees of Weaver Creek Spawning Channel for assistance in the field and logistical support. C. O'Connor, A. Colotelo, K. Hanson, and M. Davis provided assistance in the field. Thanks to J. Hills, V. Ives, J. Carter, L. Caillaud, and M. Dupoux for conducting the laboratory assays and Chum Salmon egg counts. N. Sopinka provided helpful editorial input during manuscript preparation. Anonymous referees provided critical comments that improved the manuscript. Research funding was provided by a National Science and Engineering Research Council of Canada (NSERC) Strategic Grant (to S. J. Cooke, S. G. Hinch, and A. P. Farrell). G. D. Raby, M. R. Donaldson, and C. K. Whitney were supported by NSERC graduate scholarships. Additional support was provided by Carleton University, the University of British Columbia, and Fisheries and Oceans Canada. S. J. Cooke and A. P. Farrell are supported by the Canada Research Chairs program.

\section{REFERENCES}

Baker, M. R., and D. E. Schindler. 2009. Unaccounted mortality in salmon fisheries: non-retention in gillnets and effects on estimates of spawners. Journal of Applied Ecology 46:752-761.

Baker, M. R., P. Swanson, and G. Young. In press. Injuries from non-retention in gillnet fisheries suppress reproductive maturation in escaped fish. Biological Conservation.

Barton, B. A. 2002. Stress in fishes: a diversity of responses with particular reference to changes in circulating corticosteroids. Integrative and Comparative Biology 42:517-525.

BCMOA (British Columbia Ministry of Agriculture). 2011. 2010 British Columbia seafood industry year in review. BCMOA, Victoria. Available: www.env.gov.bc.ca/omfd. (April 2012).

Bendock, T., and M. Alexandersdottir. 1993. Hooking mortality of Chinook Salmon released in the Kenai River, Alaska. North American Journal of Fisheries Management 13:540-549.

Brett, J. R. 1995. Energetics. Pages 1-68 in C. Groot, L. Margolis, and W. C. Clarke, editors. Physiological ecology of Pacific salmon. University of British Columbia Press, Vancouver.

Broadhurst, M. K., C. A. Gray, D. D. Reid, M. E. L. Wooden, D. J. Young, J. A. Haddy, and C. Damiano. 2005. Mortality of key fish species released by recreational anglers in an Australian estuary. Journal of Experimental Marine Biology and Ecology 321:171-179.

Broadhurst, M. K., P. Suuronen, and A. Hulme. 2006. Estimating collateral mortality from towed fishing gear. Fish and Fisheries 7:180-218.

Brouwer, S. L., J. C. Groeneveld, and B. Blows. 2006. The effects of appendage loss on growth of South African west coast rock lobster Jasus lalandii. Fisheries Research 78:236-242.

Buchanan, S., A. P. Farrell, J. Fraser, P. Gallaugher, R. Joy, and R. Routledge. 2002. Reducing gill-net mortality of incidentally caught Coho Salmon. North American Journal of Fisheries Management 22:1270-1275.

Butcher, P. A., M. K. Broadhurst, K. C. Hall, and S. J. Cooke. 2011. Postrelease survival and physiology of angled luderick (Girella tricuspidata) 
after confinement in keeper nets in an Australian estuary. ICES Journal of Marine Science 68:572-579.

Butcher, P. A., M. K. Broadhurst, K. C. Hall, B. R. Cullis, and R. G. Nicoll. 2010. Scale loss and mortality in angled-and-released eastern Sea Garfish (Hyporhamphus australis). ICES Journal of Marine Science 67:522-529.

Campbell, M. D., R. Patino, J. Tolan, R. Strauss, and S. L. Diamond. 2010. Sublethal effects of catch-and-release fishing: measuring capture stress, reflex impairment, and predation risk using a condition index. ICES Journal of Marine Science 67:513-521.

Cech, J. J., Jr., M. McEnroe, and D. J. Randall. 2004. Coho Salmon haematological, metabolic and acid-base changes during exercise and recovery in sea water. Journal of Fish Biology 65:1223-1232.

Chittenden, C. M., M. C. Melnychuk, D. W. Welch, and R. S. McKinley. 2010. An investigation into the poor survival of an endangered Coho Salmon population. PLoS (Public Library of Science) ONE [online serial] 5(5): e10869.

Clark, T. D., M. R. Donaldson, S. M. Drenner, S. G. Hinch, D. A. Patterson, J. Hills, V. Ives, J. J. Carter, S. J. Cooke, and A. P. Farrell. 2011a. The efficacy of field techniques for obtaining and storing blood samples from fishes. Journal of Fish Biology 79:1322-1333.

Clark, T. D., M. R. Donaldson, S. Pieperhoff, S. M. Drenner, A. Lotto, S. J. Cooke, S. G. Hinch, D. A. Patterson, and A. P. Farrell. 2012. Physiological benefits of being small in a changing world: response of Coho Salmon (Oncorhynchus Kisutch) to an acute thermal challenge and a simulated capture event. PLoS (Public Library of Science) ONE [online serial] 7:e39079.

Clark, T. D., K. M. Jeffries, S. G. Hinch, and A. P. Farrell. 2011b. Exceptional aerobic scope and cardiovascular performance of Pink Salmon (Oncorhynchus gorbuscha) may underlie resilience in a warming climate. Journal of Experimental Biology 214:3074-3081.

Cook, K. V., S. H. McConnachie, K. M. Gilmour, S. G. Hinch, and S. J. Cooke. 2011. Fitness and behavioral correlates of pre-stress and stressinduced plasma cortisol titers in Pink Salmon (Oncorhynchus gorbuscha) upon arrival at spawning grounds. Hormones and Behavior 60:489-497.

Cooke, S. J., G. T. Crossin, D. A. Patterson, K. K. English, S. G. Hinch, J. L. Young, R. Alexander, M. C. Healey, G. Van Der Kraak, and A. P. Farrell. 2005. Coupling non-invasive physiological assessments with telemetry to understand inter-individual variation in behaviour and survivorship of Sockeye Salmon: development and validation of a technique. Journal of Fish Biology 67:1342-1358.

Cooke, S. J., S. G. Hinch, G. T. Crossin, D. A. Patterson, K. K. English, M. C. Healey, J. M. Shrimpton, G. Van Der Kraak, and A. P. Farrell. 2006. Mechanistic basis of individual mortality in Pacific salmon during spawning migrations. Ecology 87:1575-1586.

Cooke, S. J., S. G. Hinch, M. R. Donaldson, T. D. Clark, E. J. Eliason, G. T. Crossin, G. D. Raby, K. M. Jeffries, M. Lapointe, K. Miller, D. A. Patterson, and A. P. Farrell. 2012. Conservation physiology in practice: how physiological knowledge has improved our ability to sustainably manage Pacific salmon during up-river migration. Philosophical Transactions of the Royal Society B 367:1757-1769.

Cooke, S. J., and L. U. Sneddon. 2007. Animal welfare perspectives on recreational angling. Applied Animal Behavior Science 104:176-198.

Cowen, L., N. Trouton, and R. E. Bailey. 2007. Effects of angling on Chinook Salmon for the Nicola River, British Columbia, 1996-2002. North American Journal of Fisheries Management 27:256-267.

Crossin, G. T., S. G. Hinch, S. J. Cooke, D. W. Welch, D. A. Patterson, S. R. M. Jones, A. G. Lotto, R. A. Leggatt, M. T. Mathes, J. M. Shrimpton, G. Van Der Kraak, and A. P. Farrell. 2008. Exposure to high temperature influences the behaviour, physiology, and survival of Sockeye Salmon during spawning migration. Canadian Journal of Zoology 86:127-140.

Davis, M. W. 2002. Key principles for understanding fish bycatch discard mortality. Canadian Journal of Fisheries and Aquatic Sciences 59:1834-1843.

Davis, M. W. 2007. Simulated fishing experiments for predicting delayed mortality rates using reflex impairment in restrained fish. ICES Journal of Marine Science 64:1535-1542.
Davis, M. W. 2010. Fish stress and mortality can be predicted using reflex impairment. Fish and Fisheries 11:1-11.

Davis, M. W., B. L. Olla, and C. B. Schreck. 2001. Stress induced by hooking, net towing, elevated sea water temperature and air in Sablefish: lack of concordance between mortality and physiological measures of stress. Journal of Fish Biology 58:1-15.

Davis, M. W., and M. L. Ottmar. 2006. Wounding and reflex impairment may be predictors for mortality in discarded or escaped fish. Fisheries Research $82: 1-6$.

Donaldson, M. R., R. Arlinghaus, K. C. Hanson, and S. J. Cooke. 2008. Enhancing catch-and-release science with biotelemetry. Fish and Fisheries 9:79105.

Donaldson, M. R., S. G. Hinch, D. A. Patterson, A. P. Farrell, J. M. Shrimpton, K. M. Miller-Saunders, D. Robichaud, J. Hills, K. A. Hruska, K. C. Hanson, K. K. English, G. Van Der Kraak, and S. J. Cooke. 2010. Physiological condition differentially affects the behavior and survival of two populations of Sockeye Salmon during their freshwater spawning migration. Physiological and Biochemical Zoology 83:446-458.

Donaldson, M. R., S. G. Hinch, D. A. Patterson, J. Hills, J. O. Thomas, S. J. Cooke, G. D. Raby, L. A. Thompson, D. Robichaud, K. K. English, and A. P. Farrell. 2011. The consequences of angling, beach seining, and confinement on the physiology, post-release behaviour and survival of adult Sockeye Salmon during upriver migration. Fisheries Research 108:133-141.

Donaldson, M. R., S. G. Hinch, G. D. Raby, D. A. Patterson, A. P. Farrell, and S. J. Cooke. 2012. Population-specific consequences of fisheries-related stressors on adult Sockeye Salmon. Physiological and Biochemical Zoology 85:729-739.

Donaldson, M. R., G. D. Raby, V. N. Nguyen, S. G. Hinch, D. A. Patterson, A. P. Farrell, M. Rudd, L. A. Thompson, C. M. O'Connor, A. H. Colotelo, S. H. McConnachie, K. V. Cook, D. Robichaud, K. K. English, and S. J. Cooke. In press. Evaluation of a simple technique for recovering Pacific salmon from capture stress: integrating comparative physiology, biotelemetry, and social science to solve a conservation problem. Canadian Journal of Fisheries and Aquatic Sciences.

Eliason, E. J., T. D. Clark, M. J. Hague, L. M. Hanson, Z. S. Gallagher, K. M. Jeffries, M. K. Gale, D. A. Patterson, S. G. Hinch, and A. P. Farrell. 2011. Differences in thermal tolerance among Sockeye Salmon populations. Science 332:109-112.

Farrell, A. P., P. Gallaugher, C. Clarke, N. DeLury, H. Kreiberg, W. Parkhouse, and R. Routledge. 2000. Physiological status of Coho Salmon (Oncorhynchus kisutch) captured in commercial nonretention fisheries. Canadian Journal of Fisheries and Aquatic Sciences 57:1668-1678.

Farrell, A. P., P. E. Gallaugher, J. Fraser, D. Pike, P. Bowering, A. K. M. Hadwin, W. Parkhouse, and R. Routledge. 2001. Successful recovery of the physiological status of Coho Salmon on board a commercial gillnet vessel by means of a newly designed revival box. Canadian Journal of Fisheries and Aquatic Sciences 58:1932-1946.

Farrell, A. P., S. G. Hinch, S. J. Cooke, D. A. Patterson, G. T. Crossin, M. Lapointe, and M. T. Mathes. 2008. Pacific salmon in hot water: applying aerobic scope models and biotelemetry to predict the success of spawning migrations. Physiological and Biochemical Zoology 81:697-708.

Ferguson, R. A., and B. L. Tufts. 1992. Physiological effects of brief air exposure in exhaustively exercised Rainbow Trout (Oncorhynchus mykiss): implications for "catch and release" fisheries. Canadian Journal of Fisheries and Aquatic Sciences 49:1157-1162.

Gale, M. K., S. G. Hinch, and M. R. Donaldson. In press. The role of temperature in the capture and release of fish. Fish and Fisheries. DOI: 10.1111/j.14672979.2011.00441.x.

Gale, M. K., S. G. Hinch, E. J. Eliason, S. J. Cooke, and D. A. Patterson. 2011. Physiological impairment of adult Sockeye Salmon in fresh water after simulated capture-and-release across a range of temperatures. Fisheries Research 112:85-95.

Gingerich, A. J., S. J. Cooke, K. C. Hanson, M. R. Donaldson, C. T. Hasler, C. D. Suski, and R. Arlinghaus. 2007. Evaluation of the interactive effects of 
air exposure duration and water temperature on the condition and survival of angled and released fish. Fisheries Research 86:169-178.

Gravel, M. A., and S. J. Cooke. 2008. Severity of barotrauma influences the physiological status, postrelease behavior, and fate of tournament-caught Smallmouth Bass. North American Journal of Fisheries Management 28:607617.

Hinch, S. G., S. J. Cooke, M. C. Healey, and A. P. Farrell. 2006. Behavioural physiology of fish migrations: salmon as a model approach. Pages 239-295 in K. A. Sloman, R. W. Wilson, and S. Balshine, editors. Behaviour and physiology of fish. Elsevier Academic Press, San Diego, California.

Hruska, K. A., S. G. Hinch, M. C. Healey, D. A. Patterson, S. Larsson, and A. P. Farrell. 2010. Influences of sex and activity level on physiological changes in individual adult Sockeye Salmon during rapid senescence. Physiological and Biochemical Zoology 83:663-676.

Hruska, K. A., S. G. Hinch, D. A. Patterson, and M. C. Healey. 2011. Egg retention in relation to arrival timing and reproductive longevity in female Sockeye Salmon (Oncorhynchus nerka). Canadian Journal of Fisheries and Aquatic Sciences 68:250-259.

Humborstad, O. B., M. W. Davis, and S. Løkkeborg. 2009. Reflex impairment as a measure of vitality and survival potential of Atlantic Cod (Gadus morhua). U.S. National Marine Fisheries Service Fishery Bulletin 107: 395-402.

Huse, I., and A. Vold. 2010. Mortality of mackerel (Scomber scombrus L.) after pursing and slipping from a purse seine. Fisheries Research 106:54-59.

Jeffries, K. M., S. G. Hinch, M. R. Donaldson, M. K. Gale, J. M. Burt, L. A. Thompson, A. P. Farrell, D. A. Patterson, and K. M. Miller. 2011. Temporal changes in blood variables during final maturation and senescence in male Sockeye Salmon Oncorhynchus nerka: reduced osmoregulatory ability can predict mortality. Journal of Fish Biology 79:449-465.

Kieffer, J. D. 2000. Limits to exhaustive exercise in fish. Comparative Biochemistry and Physiology 126A:161-179.

Lee, C. G., A. P. Farrell, A. Lotto, M. J. MacNutt, S. G. Hinch, and M. C. Healey. 2003. The effect of temperature on swimming performance and oxygen consumption in adult Sockeye (Oncorhynchus nerka) and Coho (O. kisutch) Salmon stocks. Journal of Experimental Biology 206: 3239-3251.

Lupes, S. C., M. W. Davis, B. L. Olla, and C. B. Schreck. 2006. Capture-related stressors impair immune system function in Sablefish. Transactions of the American Fisheries Society 135:129-138.

Macdonald, J. S., M. G. G. Foreman, T. Farrell, I. V. Williams, J. Grout, A. Cass, J. C. Woodey, H. Enzenhofer, W. C. Clarke, R. Houtman, E. M. Donaldson, and D. Barnes. 2000. The influence of extreme water temperatures on migrating Fraser River Sockeye Salmon (Oncorhynchus nerka) during the 1998 spawning season. Canadian Technical Report of Fisheries and Aquatic Sciences 2326.

Martins, E. G., S. G. Hinch, D. A. Patterson, M. J. Hague, S. J. Cooke, K. M. Miller, M. F. Lapointe, K. K. English, and A. P. Farrell. 2011. Effects of river temperature and climate warming on stock-specific survival of adult migrating Fraser River Sockeye Salmon (Oncorhynchus nerka). Global Change Biology 17:99-114.

Mathes, M. T., S. G. Hinch, S. J. Cooke, G. T. Crossin, D. A. Patterson, A. G. Lotto, and A. P. Farrell. 2010. Effect of water temperature, timing, physiological condition, and lake thermal refugia on migrating adult Weaver Creek Sockeye Salmon (Oncorhynchus nerka). Canadian Journal of Fisheries and Aquatic Sciences 67:70-84.

McConnachie, S. H., K. V. Cook, D. A. Patterson, K. M. Gilmour, S. G. Hinch, A. P. Farrell, and S. J. Cooke. 2012. Consequences of acute stress and cortisol manipulation on the physiology, behavior, and reproductive outcome of female Pacific salmon on spawning grounds. Hormones and Behavior 62:67-76.

McDonald, D. G., and C. L. Milligan. 1992. Chemical properties of the blood. Pages 56-113 in W. S. Hoar, D. J. Randall, and A. P. Farrell, editors. Fish physiology, volume 12, part B: the cardiovascular system. Academic Press: San Diego, California.
McRae, D. M., and P. H. Pearse. 2004. Treaties and transition: towards a sustainable fishery on Canada's Pacific coast. Fisheries and Oceans Canada, Report, Vancouver. Available: www.pac.dfo-mpo.gc.ca/publications/pdfs/jtfeng.pdf. (April 2012).

Meka, J. M., and S. D. McCormick. 2005. Physiological response of wild Rainbow Trout to angling: impact of angling duration, fish size, body condition, and temperature. Fisheries Research 72:311-322.

Miller, K. M., A. D. Schulze, N. Ginther, L. Shaorong, D. A. Patterson, A. P. Farrell, and S. G. Hinch. 2009. Salmon spawning migration: metabolic shifts and environmental triggers. Comparative Biochemistry and Physiology 4D:75-89.

Miyakoshi, Y., and S. Kudo. 1999. Mark-recapture estimation of escapement of Masu Salmon Oncorhynchus masou with a comparison to a fence count. North American Journal of Fisheries Management 19:1108-1111.

Naughton, G. P., M. A. Jepson, C. A. Peery, C. V. Brun, and J. C. Graham. 2009. Effects of temporary tributary use on escapement estimates of adult fall Chinook Salmon in the Deschutes River, Oregon. North American Journal of Fisheries Management 29:1511-1518.

Nelson, T. C., M. L. Rosenau, and N. T. Johnston. 2005. Behavior and survival of wild and hatchery-origin winter Steelhead spawners caught and released in a recreational fishery. North American Journal of Fisheries Management 25:931-943.

Parker, R. R., E. C. Black, and P. A. Larkin. 1959. Fatigue and mortality in trollcaught Pacific salmon (Oncorhynchus). Journal of the Fisheries Research Board of Canada 16:429-448.

Parsons, A. L., and J. R. Skalski. 2010. Quantitative assessment of salmonid escapement techniques. Reviews in Fisheries Science 18:301-314.

Quinn, T. P. 1999. Variation in Pacific salmon reproductive behaviour associated with species, sex and levels of competition. Behaviour 136:179-204.

Quinn, T. P., and G. B. Buck. 2001. Size- and sex-selective mortality of adult Sockeye Salmon: bears, gulls, and fish out of water. Transactions of the American Fisheries Society 130:995-1005.

Quinn, T. P., D. M. Eggers, J. H. Clark, and H. B. Rich Jr. 2007. Density, climate, and the processes of prespawning mortality and egg retention in Pacific salmon (Oncorhynchus spp.). Canadian Journal of Fisheries and Aquatic Sciences 64:574-582.

Raby, G. D., M. R. Donaldson, S. G. Hinch, D. A. Patterson, A. G. Lotto, D. Robichaud, K. K. English, W. G. Willmore, A. P. Farrell, M. W. Davis, and S. J. Cooke. 2012. Validation of reflex indicators for measuring vitality and predicting the delayed mortality of wild Coho Salmon bycatch released from fishing gears. Journal of Applied Ecology 49:90-98.

Rajwani, K. N., and C. J. Schwarz. 1997. Adjusting for missed tags in salmon escapement surveys. Canadian Journal of Fisheries and Aquatic Sciences 54:800-808.

Roberts, L. W., P. A. Butcher, M. K. Broadhurst, and B. R. Cullis. 2011. Using a multi-experimental approach to assess the fate of angled-and-released Yellowtail Kingfish (Seriola lalandi). ICES Journal of Marine Science 68: 67-75.

Schubert, N. D. 2000. The 1994 Stellako River Sockeye Salmon (Oncorhynchus nerka) escapement: evaluation of pooled Petersen and stratified markrecapture estimates of a known population. Canadian Technical Report of Fisheries and Aquatic Sciences 2303.

Schwarz, C. J., R. E. Bailey, J. R. Irvine, and F. C. Dalziel. 1993. Estimating salmon spawning escapement using capture-recapture methods. Canadian Journal of Fisheries and Aquatic Sciences 50:1181-1197.

Suski, C. D., S. J. Cooke, and B. L. Tufts. 2007. Failure of low-velocity swimming to enhance recovery from exhaustive exercise in Largemouth Bass (Micropterus salmoides). Physiological and Biochemical Zoology 80:78-87. Thompson, L. A., S. J. Cooke M. R. Donaldson, K. C. Hanson, A. Gingerich, T. Klefoth, and R. Arlinghaus. 2008. Physiology, behavior, and survival of angled and air-exposed Largemouth Bass. North American Journal of Fisheries Management 28:1059-1068.

Tucker, S., M. Trudel, D. W. Welch, J. R. Candy, J. F. T. Morris, M. E. Thiess, C. Wallace, D. J. Teel, W. Crawford, E. V. Farley Jr., and T. D. Beacham. 
2009. Seasonal stock-specific migrations of juvenile Sockeye Salmon along the west coast of North America: implications for growth. Transactions of the American Fisheries Society 138:1458-1480.

Vander Haegen, G. E., C. E. Ashbrook, K. W. Yi, and J. F. Dixon. 2004. Survival of spring Chinook Salmon captured and released in a selective commercial fishery using gill nets and tangle nets. Fisheries Research 68: $123-133$.
Vincent-Lang, D., M. Alexandersdottir, and D. McBride. 1993. Mortality of Coho Salmon caught and released using sport tackle in the Little Susitna River, Alaska. Fisheries Research 15:339-356.

Wendelaar Bonga, S. E. 1997. The stress response in fish. Physiological Reviews 77:591-625.

Wood, C. M., J. D. Turner, and M. S. Graham. 1983. Why do fish die after severe exercise? Journal of Fish Biology 22:189-201. 